\title{
DAS CRIOULAS DE CONCEIÇÃO: (INTER) AÇÕES DO MOVIMENTO INTERCULTURAL IDENTIDADES
}

\section{Madalena Zaccara}

\section{Resumo}

Localizada no município de Salgueiro, Pernambuco, Conceição das Crioulas é uma comunidade quilombola com uma história oral que remete à chegada de seis negras livres à região onde estabeleceram as bases da comunidade. As mulheres direcionam a vida comunitária desde a sua fundação, passando pela resistência à expropriação da terra e à transmissão de sua cultura. Elas investem na educação como instrumento de resistência e conquista. É a partir dessa proposta, que a arte relacional ou contextual praticada pelo Movimento Intercultural IDENTIDADES, onde o artista é participante da história imediata, encontra seu espaço de ação na comunidade. O texto visa analisar esse processo de (inter) ação artística do movimento no universo das crioulas de Conceição.

\section{Palavras-chave:}

Arte Relacional, Gênero, Educação, Conceição das Crioulas, Movimento Intercultural IDENTIDADES.

\author{
Primeiro o ferro marca \\ a violência nas costas \\ depois o ferro alisa \\ a vergonha nos cabelos \\ $\mathrm{Na}$ verdade o que se precisa \\ é jogar o ferro fora \\ e quebrar todos os elos \\ dessa corrente de desesperos. ${ }^{1}$
}

O comércio de escravos no Atlântico envolveu a maior migração transoceânica da história. Mais de cinco milhões e meio de africanos embarcados na África desembarcaram nas Américas, incluindo o Brasil. Era um negócio lucrativo que movimentava a indústria naval, o sistema financeiro europeu, a indústria armamentista e o plantio da cana de açúcar além de outras atividades. No Brasil, Recife foi o quinto maior centro organizado de tráfico transatlântico de escravos do mundo. Calcula-se que mais de 1.350 viagens foram feitas da África

\section{Abstract}

Located in the city of Salgueiro, Pernambuco, Conceição das Crioulas is a quilombola community with an oral history that refers to the arrival of six freed women to the region where they established the foundation of the community. The women directed the community life since its founding, passing through the resistance of the land expropriation and the transmission of their culture. They invest in the education as a tool of resistence and conquest. It is from this proposal, that the relational or contexted art practiced by the Intercultural Movement IDENTITIES, where the artist is the participant of the imeddiate history, finds its space in the community action. The text has as goal to analyze this process of artistic (inter) action of the movement in the universe of the crioulas of Conceição.

Keywords:

Relational Art, Gender, Education, Conceição das Crioulas, Intercultural Movement IDENTITIES.

para Recife nos quase três séculos de tráfico (SOUZA LEAO; ALBUQUERQUE; VERGOLINO, 2015). O apogeu do tráfico para terras pernambucanas ocorreu entre 1816 e 1820 e os escravos eram as mãos e os pés dos cidadãos mais abastados da região naquele momento. Além das relações de trabalho entre senhor e escravo existia toda uma ideologia da escravidão que se constituía em uma maneira de viver e implicava em uma simbologia de poder e de status naquela sociedade.

Mesmo após 1831, quando o tráfico tornouse ilegal, ele continuou de forma clandestina e escravos eram desembarcados no litoral pernambucano e redistribuídos aos compradores. A extinção gradual deste comércio foi resultado da pressão inglesa e das condições locais uma vez que, gradativamente, importar escravos para a indústria açucareira já não apresentava as mesmas 
vantagens iniciais, dada a excessiva oferta de escravos no território pernambucano (CARVALHO, 2010).

O Brasil - e Pernambuco em particular - apresenta, dentro desse quadro escravagista, uma memória quase nunca registrada de resistência à escravidão que se manifesta concretamente através dos variados modelos de organização social e espacial e estratégias diversas encontradas pelos cativos em vários períodos onde se fez presente a escravidão no país.

Nunca faltaramfugasem Recifee demais localidades pernambucanas. Sem partir para uma revolta aberta os escravizados encontraram fórmulas de oposição ao cativeiro em alternativas sociais (sendo o quilombo a forma opositiva mais radical) que pouco a pouco despertavam a construção de uma consciência negra baseada na solidariedade e, por que não dizer, na sobrevivência. A fuga era uma decisão extrema dada a hostilidade das alternativas na época. Ela envolvia riscos que iam desde a perseguição e captura pelos capitães de mato até a incerteza do destino nessa comunidade alternativa a qual o fugitivo passaria a pertencer: o quilombo. Quando o escravo fugia, amparado pela possibilidade de um conceito vago de liberdade, ele tinha que se reeducar para ela, o que implicava na aprendizagem da resistência, das técnicas de guerrilha e da adaptação a outras regras diferentes das tantas que ele havia experimentado desde sua captura na África, passando pela travessia no Atlântico e pelas mãos dos seus muitos senhores.

O caminho para a liberdade passava, portanto, por uma conquista principal: a recuperação de sua humanidade natural através do estabelecimento de laços de pertencimento. Sua luta posterior pelo direito ao trabalho e pela conquista gradual de participação dentro do sistema passou, em seu início, pela etapa da busca de um espaço próprio, novo, e pela sua integração a ele.

Os processos de ocupação territorial por quilombos em Pernambuco se relacionam com o contexto sócio-político do período no qual teve início cada uma das comunidades quilombolas. As mais antigas originaram-se quase sempre de fugas de escravos provenientes de fazendas locais e mesmo de locais mais distantes. Em sua maior parte, elas ocupavam terras que não interessavam aos fazendeiros seus contemporâneos. Eram terras sem dono, terras de ninguém. Posteriormente, já no final do século:

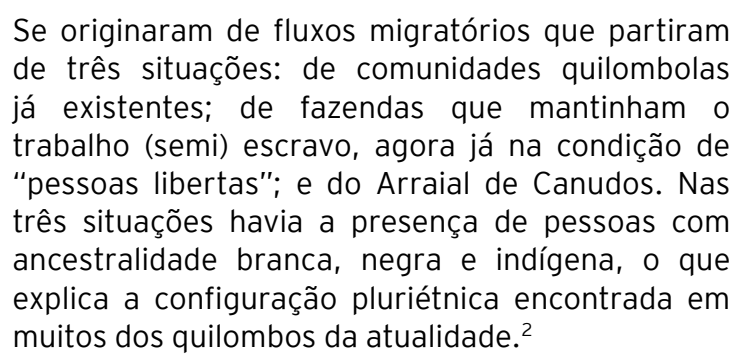

Muitas das pessoas que migravam haviam acumulado algum dinheiro proveniente do trabalho nas fazendas que elas investiram na compra ou arrendamento de terras onde trabalharam na produção agrícola. É nesse contexto que surgem novas comunidades que, nesse deslocamento, às vezes estabeleciam relações de sociabilidade com os indígenas locais. É nesse contexto também, que surgiu a comunidade quilombola Conceição das Crioulas, suporte e meio da arte relacional praticada pelo Movimento Intercultural IDENTIDADES, objeto principal do nosso texto.

\section{O papel da mulher na sociedade patriarcal e escravocrata brasileira}

Dentro da pirâmide social estruturada na sociedade escravocrata brasileira os brancos ficavam no topo, distribuídos em posições melhores em relação ao alto desta por meio do seu poder aquisitivo. Em um degrau abaixo estavam as mulheres, brancas que eram, apesar de brancas, cidadãs de segunda categoria. Em baixo desta construção social ficavam os negros e os indígenas considerados inferiores. Em um nível mais inferior ainda estavam as mulheres negras escravas tanto por serem mulheres, como por serem negras e escravas. Ser mulher, e ser escrava dentro de uma sociedade opressora e sexista, significava ser vulnerável à exploração econômica, sexual e alvo de injustiças e humilhações por parte das demais camadas sociais. A escrava sofria o assédio, o estupro e a opressão generalizada por parte do senhor e não escapava dos ciúmes da sinhá que se vingava como podia e sempre na mulher.

Por outro lado, as mulheres escravas constituíam a maioria dos libertos e, embora reste sempre a ideia de que, generosamente, o senhor de escravos libertasse a escrava como uma espécie de recompensa pela submissão sexual, alguns historiadores se posicionam no sentido de que foram elas que conquistaram essa alforria 
(CARVALHO, 2010, p.222). Uma liberdade que era mais facilmente aceita pelos donos do poder por questões de gênero uma vez que o fato de ser mulher tornava o caminho para a verdadeira liberdade bem mais difícil e então a alforria fornecia uma liberdade "de direito", mas não "de fato". Essa liberdade concedida não assegurava possibilidades econômicas de mantê-la, nem a incluía em um grupo de pertencimento. As mulheres, portanto, tinham um caminho bem mais árduo em direção à liberdade, mesmo quando alforriadas.

E era um caminhar extremamente difícil não só para as mulheres negras, embora a estas coubesse o ônus maior. Afinal, brancas, negras ou mulatas estamos tratando aqui de corpos - marionetes. Um corpo sobre o qual: "as relações de poder têm alcance imediato sobre ele; elas o investem, o marcam, o dirigem, o supliciam, sujeitam-no a trabalhos, obrigam-no a cerimônias, exigemIhe sinais" (FOUCAULT, 1989, p. 28). Esse poder afirmou-se no Brasil patriarcal e escravocrata tanto sobre a mulher branca quanto sobre a negra. Sobre a situação da sinhá branca da casa grande assim se manifesta Gilberto Freyre (apud QUINTAS, 2008, p. 52):

Da mulher-esposa, quando vivo ou ativo o marido, não se queria ouvir a voz na sala, entre conversas de homem, a não ser pedindo vestido novo, cantando modinha, rezando pelos homens; quase nunca aconselhando ou sugerindo o que quer que fosse de menos doméstico, de menos gracioso, de menos gentil; quase nunca metendo-se em assuntos de homem.

$\mathrm{Na}$ esteira das dificuldades rumo à liberdade, coube a ambas, branca e negra, o ônus de sua liberdade gradativa. Mecanismos de sobrevivência pressionaram a busca de alternativas. Depois da abertura dos portos em 1808, de acordo com Marcos J. M. de Carvalho (2010, p. 77):

Muitas mulheres que tentavam fazer valer suas vontades, enfrentando as duras regras não escritas do patriarcado preferiram morar na cidade. Lá havia mais oportunidades e alternativas para se ganhar a vida, principalmente para as mais decididas, tendo ou não filhos.

Os núcleos urbanos existentes ofereciam oportunidades de emprego para mulheres livres no serviço doméstico tradicionalmente destinado às mais pobres onde se incluía a negra liberta. A alternativa para as alfabetizadas e brancas era a função de professora das primeiras letras, piano ou línguas estrangeiras às crianças de famílias mais abastadas. Cabia, porém ao negro, mulher ou homem, o ônus de provar, em um espaço social onde a recaptura era tolerada e pouco investigada pelas autoridades; onde era necessário defender todo o tempo a liberdade conquistada, que ele era legalmente e realmente livre. A cor da pele era, em si, um entrave à liberdade "de fato". Presumia-se a condição de escravo para uma pessoa de cor e a circulação urbana tornava-se perigosa. Em tal situação, a conquista de um espaço econômicosocial para viver tornava-se uma questão de sobrevivência e não é de se estranhar que esse espaço devesse ser o mais isolado possível da comunidade branca.

Um exemplo coletivo dessa busca por um espaço é a comunidade quilombola Conceição das Crioulas abrigada no sertão de Pernambuco. Sua história, baseada em uma narrativa oral, remete às suas mulheres fundadoras. Trata-se de um quilombo fundado por mulheres e onde, até hoje, são elas as protagonistas das lutas e conquistas do grupo de pertencimento por elas criado. Os padrões discriminatórios em relação às mulheres nas tantas sociedades, cronologicamente e espacialmente diversificadas, parecem nesse espaço social ali construído terem se erradicado ou pelo menos amenizado. Naquele espaço, as mulheres se organizaram na construção de uma nova sociedade utilizando-se dos instrumentos possíveis para a desconstrução de ideias e atitudes que viessem a negar seus direitos dentro do quadro maior dos próprios direitos humanos.

\section{Sobre a comunidade quilombola Conceição das Crioulas: um conceito de nação conjugado no feminino?}

Localizada no município de Salgueiro, Pernambuco, Conceição das Crioulas tem uma história oral que remete à luta de seis negras livres que chegaram à região, arrendaram uma área e, graças ao cultivo, fiação e venda do algodão (que era comercializado na cidade de Flores), conseguiram arrendar três léguas de terra. Gleba esta que depois compraram e escrituraram em um cartório de uma localidade próxima denominada Torre, em 1802, por um escrivão de nome Pedro José Delgado. Essa tradição oral de cunho quase mitológico estabelece a forma de ocupação da terra pela comunidade no início do século XIX. 
Os três mil quinhentos e cinquenta e dois habitantes atuais do distrito ocupam uma área de 16.885,0678 hectares no povoamento central. A maioria dos habitantes habita os "sítios" que se espalham no território comum ${ }^{3}$. Esta comunidade quilombola faz parte das muitas já reconhecidas pelo Estado Brasileiro por meio de "certificação feita pela Fundação Cultural Palmares (FCP) (certificação do autorreconhecimento) e da abertura de processo de regularização dos territórios quilombolas pelo Instituto Nacional de Colonização e Reforma Agrária (INCRA)"'4. Conceição das Crioulas, juntamente com outras comunidades semelhantes espalhadas pelo território brasileiro formam grupos de resistência negra à escravidão inicial e à exploração de mão de obra posterior.

No início do século $X X$, as terras adquiridas diminuíram de extensão em virtude de invasões e aquisições ilícitas por parte de fazendeiros. 0 território foi encolhendo e só em 2014 a posse da terra foi legitimada pelo governo federal e os fazendeiros invasores intimados a abandonar a terra. O dia vinte e dois de setembro daquele ano passou a ser um dia histórico para a comunidade. Naquela data, foram entregues pelo INCRA três títulos de domínio de cinco imóveis rurais que estavam dentro do Território Quilombola. Dessa maneira, aproximadamente 898 hectares passaram a compor efetivamente o patrimônio coletivo da comunidade, beneficiando 750 famílias. A titulação ocorreu mediante a outorga de título coletivo e pró-indiviso à comunidade, em nome da Associação Quilombola de Conceição das Crioulas (AQCC) ${ }^{5}$.

As mulheres e suas ações têm forte significação dentro desta comunidade desde a sua fundação, passando pela resistência à expropriação da terra, à transmissão de sua cultura. Essa resistência está intimamente ligada à formação das lideranças que compõem a estrutura política em Conceição das Crioulas, lideranças que se conjugam no feminino tanto no que diz respeito às referências históricas quanto às do dia a dia comunitário. Apesar do empenho atual de alguns homens no sentido de participação nas lutas pelos direitos quilombolas ainda predomina maciçamente a presença da mulher, guerreira e educadora, nas decisões comunitárias:

O papel da mulher é assegurado na descendência.

É "nelas que tudo começa": a fundação da comunidade (incluindo a compra da terra), a origem do nome, a defesa do território frente às "invasões" das quais resultaram expropriações; elas também estão presentes na execução e perpetuação de determinadas práticas ou atividades culturais como os ofícios de benzedeira e parteira e na produção de trabalhos artesanais. As mulheres que se dedicam a essas atividades dizem ter aprendido com suas mães ou avós. (LEITE, 2010)

A batalha prossegue. As mulheres de Conceição das Crioulas se transformaram, romperam com a tradição secular de subserviência. Suas conquistas as afastaram da condição de mero celeiro de mão de obra das cidades vizinhas. A negritude hoje não é mais motivo de vergonha, mas de orgulho e a educação é o instrumento de conquista na luta pelos seus direitos. Nas palavras de Maria Diva da Silva Rodrigues:

As escolas ensinavam para a gente, de forma bem sutil, que era feio ser negro, que nosso cabelo por ser pixaim era feio. Então era pra se dizer que era moreno, moreno escuro, moreno claro. Negar que era de Conceição porque ser de Conceição era ruim, porque era um lugar atrasado onde só tinha negro e negro não era uma coisa boa. (Maria Diva da Silva Rodrigues, In CARRION, 2013, p. 54)

Elas interromperam com esse discurso. E propuseram para as escolas um currículo alternativo no qual os valores ancestrais fossem contemplados e que contribuísse para semear o orgulho no lugar da vergonha das suas origens. Hoje, Gilvania, Aparecida Mendes, Márcia Jucilene, Maria Diva e Valdeci entre tantas outras são mulheres que sabem os caminhos que devem ser percorridos. São os pilares atuais da comunidade. Abrem caminhos, Rotas diversas das de suas antepassadas fundadoras, mas não menos importantes. Elas objetivam novas formas de liberdade e a identidade como princípios norteadores. A liberdade física, meta das antigas escravas, transformou-se na luta política pela cidadania em toda a sua plenitude.

A experiência educacional de Conceição das Crioulas é considerada referência para o movimento quilombola e outras organizações que trabalham com educação. Seu projeto é diferenciado e trabalha com uma concepção e práxis na qual os valores, a cultura, os costumes, as tradições, a sabedoria das pessoas mais velhas e a história dos antepassados fazem parte do processo educativo.

A presença e a consciência do papel da mulher nas 
conquistas da comunidade são marcos a serem observados em um espaço social que poderia englobar um conceito de nação. Uma nação, em seu sentido político moderno: uma comunidade de indivíduos vinculados social e economicamente geralmente de um mesmo grupo étnico, que compartilham certo território, que reconhecem a existência de um passado comum, que têm uma visão de futuro em comum e que acreditam que esse futuro será melhor se se mantiverem unidos do que separados. A partir dessa premissa, Conceição das Crioulas é uma nação. Uma nação onde os padrões sociais e culturais discriminatórios com relação às mulheres presentes em maior ou menor grau em todas as regiões do planeta parecem não mais existir. Nela, as mulheres que se destacaram na luta pela aquisição, construção e recuperação das terras que ocupam e que hoje lutam pela construção de uma identidade étnica estão no comando.

A abertura dessas mulheres para novos horizontes passa por uma emancipação pela educação. A consciência sobre este instrumento libertador está presente nas palavras de sua principal líder política Gilvania Maria Silva quando fala sobre sua comunidade:

mergulhada numa busca constante de ações direcionadas à educação, à saúde e ao reconhecimento da sua cultura, do processo da reconstrução da identidade e de seu território. Mesmo diante do cenário de dúvidas, a educação era entendida pelos seus moradores (as) como atividade importante. (SILVA, 2013, p. 47)

É nessa conjuntura, a partir dessa proposta, que prioriza a educação como veículo de emancipação, que a arte relacional ou contextual praticada pelo Movimento Intercultural IDENTIDADES, no qual o artista, participante da história imediata, encontra seu espaço na comunidade. Esse engajamento, essa forma de criar artístico, não visa o sublime ou o transcendente; sua proposta se volta para a possibilidade de transformação do social e nele encontra seus instrumentos. A arte, devemos lembrar, pode ser o último reservatório do imaginário a escapar de ser incorporado/ apropriado pelo sistema que hoje serve ao capitalismo neoliberal e o seu consumir ideológico. As práticas artísticas que envolvem a política relacional podem abrigar um sonho para além das servidões e ser uma promessa de reconciliação com o humano em sua expressão maior. A colaboração com a comunidade através da arte-educação é o objetivo do movimento.

\section{Sobre o Movimento Cultural IDENTIDADES}

A história da relação entre arte e política aparece sempre ao longo da história da arte. Ela, a arte, serviu a religiões ou estados, passando sua mensagem em incontáveis situações no tempo e no espaço. O artista pode abrir caminhos, resistindo e isolando-se do ruído circundante e gerar novas propostas e ressonâncias.

A arte é aquilo que resiste, segundo Deleuze (1999). Para Jacques Rancière (2009, p.26), ela é um agente transformador pela sua capacidade de reconfigurar o sensível e é a partir "do recorte sensível do comum, da comunidade, das formas de sua visibilidade e de sua disposição, que se coloca a questão da relação estética/politica". Esse olhar priorizaria a noção de envolvimento em relação ao desenvolvimento (idem).

Para Nicolas Bourriaud (2009, p.31), cabe ao artista a tarefa de "devolver concretude ao que se furta à nossa vida" o que ele faria rompendo com a lógica da sociedade do espetáculo, com a escala diluidora da globalização e tentando reconstruir e restituir fé a um mundo cuja dominação cultural pelo capitalismo avançado conduz a um cotidiano transformado em um produto de consumo. Para ele, a possibilidade desta arte relacional "uma arte que toma como horizonte teórico a esfera das relações humanas e seu contexto social" (ibidem, p. 19) atende aos objetivos estéticos, culturais e políticos postulados pela contemporaneidade e estaria contribuindo para a preparação de um mundo futuro. Pressente-se já, através do seu pensamento, a necessidade de retomada de uma política ligada a uma transformação estética, ou, como quer Carlos Vidal (1997, p 22) “uma refundação da linguagem estética que ultrapasse a fatalidade do triunfo da industrialização do pensamento".

A arte contemporânea desenvolveria, portanto, um projeto político quando se empenha, por exemplo, em investir e problematizar as esferas das relações humanas. Essa condição corresponde, hoje, à iniciativa de artistas que mergulham no campo ampliado da criatividade, no qual o caráter político é relacionado ao fato de uma integração do trabalho artístico com a vida. O trabalho da arte, nas suas novas formas, ultrapassa a antiga produção de 
objetos destinados a serem vistos e consumidos e investe em novos horizontes que funcionam ora como mapas que orientam seu movimento, ora como motor de um desejo de caminhar novamente em busca de um ideal. A liberdade conceitual, imaginativa e perceptiva das práticas artísticas que envolvem a política pode abrigar um sonho para além das servidões e uma promessa de reconciliação com o humano em sua expressão maior. Sua proposta encontra-se para além das múltiplas grades com as quais o capital burocratiza e regula a arte incidindo em sua produção.

Para a concretização desta possibilidade, desta nova práxis, o envolvimento do artista, segundo José Carlos de Paiva (2009, p. 53), deve procurar modelos que ultrapassem as fragilidades e invistam nas possibilidades utópicas do mundo contemporâneo, "em contextos sociais precisos, onde se promoveu uma aproximação epidérmica". Tomando-se o cotidiano como base, "pode-se criar diferentes versões da realidade", afirma Bourriaud (2009, p.83). Nestas condições, a arte se apresentaria "como uma mesa de montagem alternativa que perturba, reorganiza ou insere as formas sociais" (idem). Caberia ao artista desprogramar a realidade para reprogramar uma estética que se pautaria em função das relações inter-humanas. Uma estética que contemple o "outro", legitimando-o. O mundo da arte e da vida estaria, então, de fato, cada vez mais fundido e a estética, como ciência do sensível, em consonância com esse novo olhar.

Conduzidos pelos artistas, os indivíduos seriam impulsionados a lutar por um ser melhor, um ser que se interessaria pelos outros, um ser coletivo, um ser político. Essas reivindicações se concretizariam a partir de uma transformação radical que englobaria a própria maneira de conceber a arte.

É trabalhando neste intervalo micropolítico, que o movimento intercultural IDENTIDADES, nascido em Porto, Portugal, se manifesta. Trata-se de um movimento artístico, atuante desde os anos 90, mais precisamente concebido em 1996, que participa dos conflitos da era pós-colonial tendo como objetivo as relações culturais diretas em vários espaços geográficos do planeta de histórico colonial português.

Atuando em comunidades situadas em três espaços geograficamente distintos e com características específicas, o movimento mobiliza artistas, professores e estudantes de arte que, fora do seu espaço de conforto buscam, através da reflexão partilhada, interagir nestes três espaços sociais. A partir de Porto, como já foi dito anteriormente, ele se relaciona com espaços de colonização lusa: Moçambique, Cabo Verde e Conceição das Crioulas, comunidade quilombola no Nordeste do Brasil.

O movimento intercultural IDENTIDADES é constituído por indivíduos que se congregam em um grupo não homogêneo tanto no que diz respeito a objetivos pessoais quanto no que diz respeito à forma de criação e expressão. Eles têm em comum o interesse pelo resgate de um perfil de identidade cultural fragmentado, destruído ou em processo de destruição, procurando um sentido para a ação artística, estabelecendo vínculos relacionais adequados aos interesses das comunidades em que atuam.

É nesse terreno intercultural "onde a história confere posturas próprias e um tempo particular perante o contemporâneo", segundo José Carlos Paiva (2009, p. 58), que os membros do grupo se assumem enquanto artistas e enquanto cidadãos. As ações artísticas de grupos como o movimento intercultural IDENTIDADES procuram construir e realizar modelos de ação dentro da realidade existente e que tenham como objetivo maior fazer a diferença.

\section{Sobre a ação do Movimento Intercultural IDENTIDADES em Conceição das Crioulas}

De acordo com José Carlos de Paiva (2007, p.18), na arena relacional em que ele próprio se move e onde também transita o movimento IDENTIDADES, "a marca da vida escolar nunca deixa de dominar". O envolvimento do movimento na comunidade quilombola Conceição das Crioulas segue essa proposta e "assume a ação como intervenção política em contextos onde a população se envolve em seu próprio desenvolvimento" (2011, p.31). Em Conceição das Crioulas, a política se faz através da arte-educação.

O envolvimento do movimento com a comunidade iniciou-se em 2003. Sua história, entretanto, remete aos primeiros contatos de José Carlos de Paiva, líder do IDENTIDADES, com a capital do Estado de Pernambuco, Recife, representando 
a GESTO Cooperativa Cultural. O contato se deu através da Fundação Joaquim Nabuco via o seu presidente, Fernando Freire e tinha como objetivo estabelecer um programa de intercâmbio artístico e cultural. Do encontro inicial resultou o projeto "Cumplicidades", que promoveu, entre os anos de 1993 a 1996, dezenas de eventos culturais em Portugal no Nordeste do Brasil (PAIVA, 2009, p.134). Para Paiva, o tempo que transcorreu entre estes primeiros contatos nordestinos, que precederam o que aconteceu com Conceição das Crioulas foi o necessário para proporcionar amadurecimento e, então, através do Centro de Cultura Luiz Freire, em 2003, estabelecer relações com a comunidade.

Em 2003, contato estabelecido, foi criada uma oficina de artes plásticas ministrada por Iva Correia e Monica Farias (de Porto) e uma de teatro que foi dada pelo ator moçambicano Rogério Manjate. Montou-se uma exposição em uma das dependências de uma escola local intitulada "Pano para Mangas" onde o movimento foi apresentado para a comunidade. Deste momento fala Monica Faria, integrante do IDENTIDADES:

\begin{abstract}
Eu, a Iva Correia, ambas viajando do Porto, e o Rogério Manjate de Moçambique tivemos a oportunidade de visitar e conhecer a comunidade através do 'movimento intercultural Identidades', a convite do Centro de Cultura Luís Freire (CCLF) e da Associação Quilombola da Conceição da Crioulas (AQCC) para realizar uma oficina de artes plásticas, principalmente para a faixa etária infantil e juvenil. O Rogério Manjate orientou uma oficina de teatro. A data escolhida foi a grande festa da 'Nossa Senhora da Conceição' a santa padroeira da comunidade, em pleno agosto sertanejo. A festa durou quinze dias e durante esse tempo organizaram-se várias oficinas: teatro, contação de histórias, história da África, artes plásticas, dança e percussão. (FARIA, 2011, p.55)
\end{abstract}

No ano seguinte, 2004, o IDENTIDADES voltou à Conceição das Crioulas para sentir as respostas da comunidade à ação inicial e ao interesse pela construção de uma base na comunidade de caráter mais permanente. A partir de uma troca de ideias com a comunidade e da explicitação das intenções do grupo, foi aprovado um programa intitulado "Deslocações" que se centrava em intervenções através das linguagens do Vídeo, do Webdesign, da Cerâmica, da Educação Visual e da Expressão Plástica. A proposta foi aceita pela comunidade e o grupo retornou em 2005 e, através da preparação de seis jovens da comunidade, durante nove dias, possibilitou-se a criação de um coletivo intitulado "Crioulas Vídeo" que passou a se constituir em mais uma ferramenta na luta pela identidade local através da produção de vídeos que divulgam a sua história e realizações. ${ }^{6}$

O Crioulas Vídeo (fig. 1) formou-se junto aos jovens da comunidade. Entre os membros foram escolhidos inicialmente seis: Marta Adelaide, Aldamir José, Martinho Mendes, Francisco Mendes, Joséane de Oliveira e Reginaldo Antônio. Posteriormente, a eles se juntaram Jocilene e Josicleide. 0 objetivo da equipe é o registro dos acontecimentos da comunidade, ter autonomia para contar sua própria história até então contada por olhares externos. Vários documentários foram produzidos desde sua criação.

Hoje, a ação do IDENTIDADES centra-se principalmente no trabalho desenvolvido com as professoras, para que elas adquiriram as competências necessárias para o ensino da arte na comunidade. O Crioulas Vídeo anda sozinho. A introdução da arte no universo da comunidade, nas palavras de Márcia Jucilene do Nascimento?, professora, transforma Conceição das Crioulas em uma "comunidade mais desenvolvida e politizada" e "ciente dos rumos e passos necessários para se chegar às conquistas importantes". É interessante recordar que, neste espaço social, o conceito erudito ocidental de arte não existe. Seus habitantes se expressam através do artesanato e das artes populares como a dança, a música e a culinária. A arte só é compreendida a partir de seus reflexos práticos sobre a comunidade e de como ela pode servi-la.

Formar professores na área artística poderia contribuir para uma forma mais ampliada de percepção e fruição da arte. Para uma ampliação da sensibilidade dos alunos o que poderia gerar outras percepções e competências sempre tendo em vista, porém, que, para uma comunidade que se propõe a andar sozinha, como é o caso de Conceição das Crioulas, e que anseia por uma educação baseada em currículo diferenciado, tendo como comparação o currículo formal que é visto como sendo externo e global, o ensino da arte deve acompanhar suas particularidades.

O projeto "Expressões Artísticas nas Escolas da Comunidade" (fig. 2) dá continuidade, hoje, às ações do IDENTIDADES em Conceição das Crioulas. 


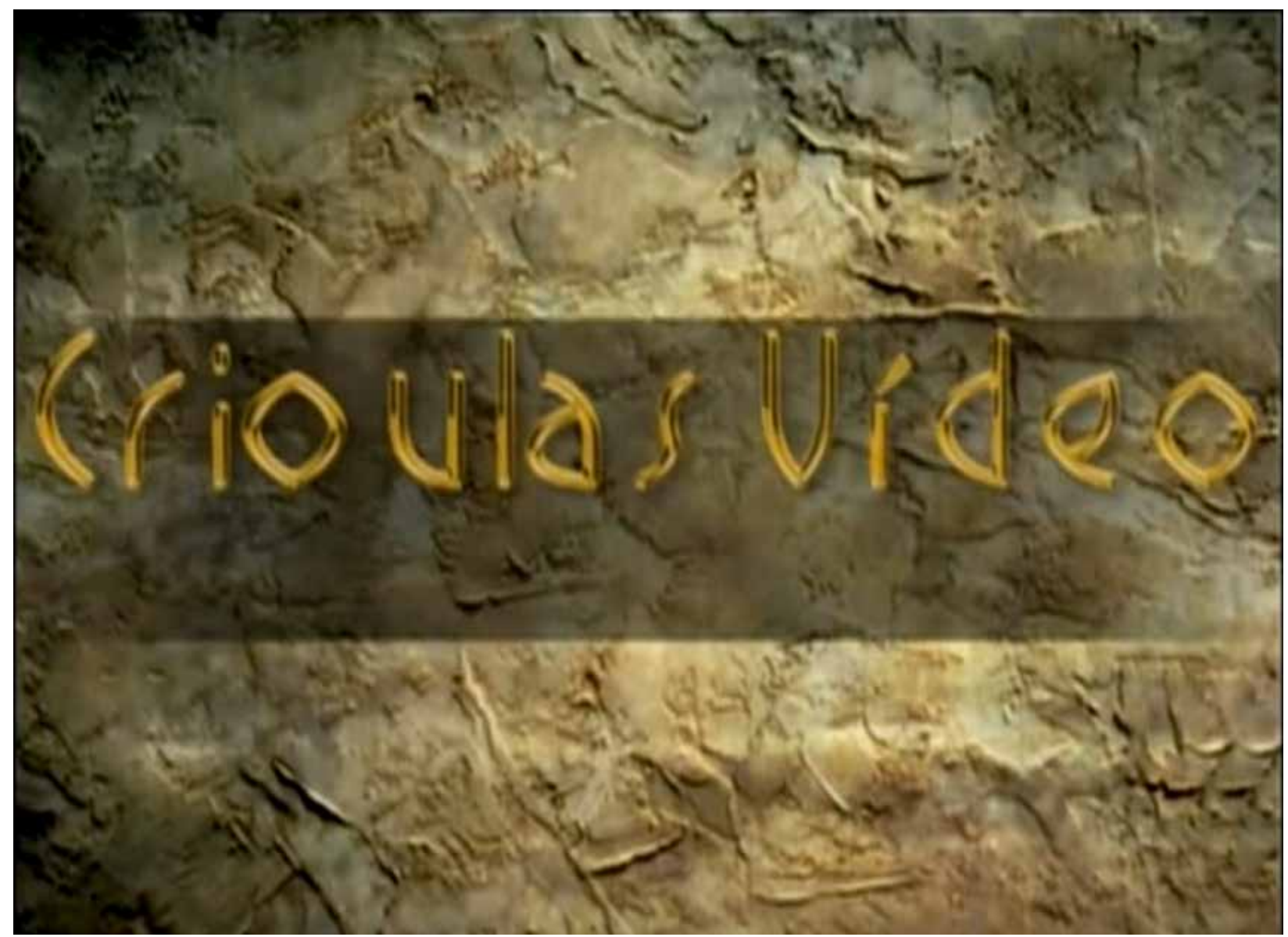

Figura 1 - Crioulas Vídeo. Serra das princesas. Documentário. Disponível em https://youtu.be/OzEfoJXIHNw

Ele visa à construção conjunta de um Currículo nas Artes que contemple a necessidade coletiva e que invista na construção de um professor apto para fazer a ponte entre o senso comum e o conhecimento teórico artístico. Elisabete Mônica Moreira Faria, a já citada participante do movimento e doutoranda em Educação Artística pela Universidade de Porto com tese na qual a pesquisa de campo foi realizada na comunidade, reforça:

A comunidade entendeu que deve integrar as diversas áreas da expressão no seu currículo, num processo de cruzamento intercultural com - IDENTIDADES. Neste contexto o projecto 'Expressões Artísticas nas Escolas da Comunidade' visa elaborar uma discussão construtiva e participativa para um Currículo nas Artes ${ }^{8}$.

Com uma proposta de educação diferenciada, a comunidade quilombola de Conceição das Crioulas pretende encontrar outras modulações para as oposições entre periferia e centro, atrasado e desenvolvido, subalterno e dominante, popular e acadêmico, a partir de relações de reciprocidade e de diálogo. A arte pode ser uma de suas rotas e o Movimento Intercultural IDENTIDADES contribui para que a comunidade a percorra. Marcia Jucilene Nascimento, professora e ativista de Conceição das Crioulas, acredita nisso. Diz ela:

Penso que Arte é o que a gente faz com amor, com dedicação, com cuidado. Ela é intencional, e pode ser representada de diversas formas e em diversos campos: político, social, religioso, cultural etc. O que é mais forte no nosso lugar é a arte de lutar coletivamente pelo bem da comunidade ${ }^{9}$.

\section{NOTAS}

1. CUTI (Luiz Silva). Ferro (In CAMARGO, 1986, p.90).

2. SERTÃO QUILOMBOLA. A formação dos quilombos no sertão pernambucano. Publicação do Centro Cultural Luís Freire. Recife: Centro Cultural Luís Freire: 2008, p.9.

3. Fonte: Relatório da Fundação Cultural 


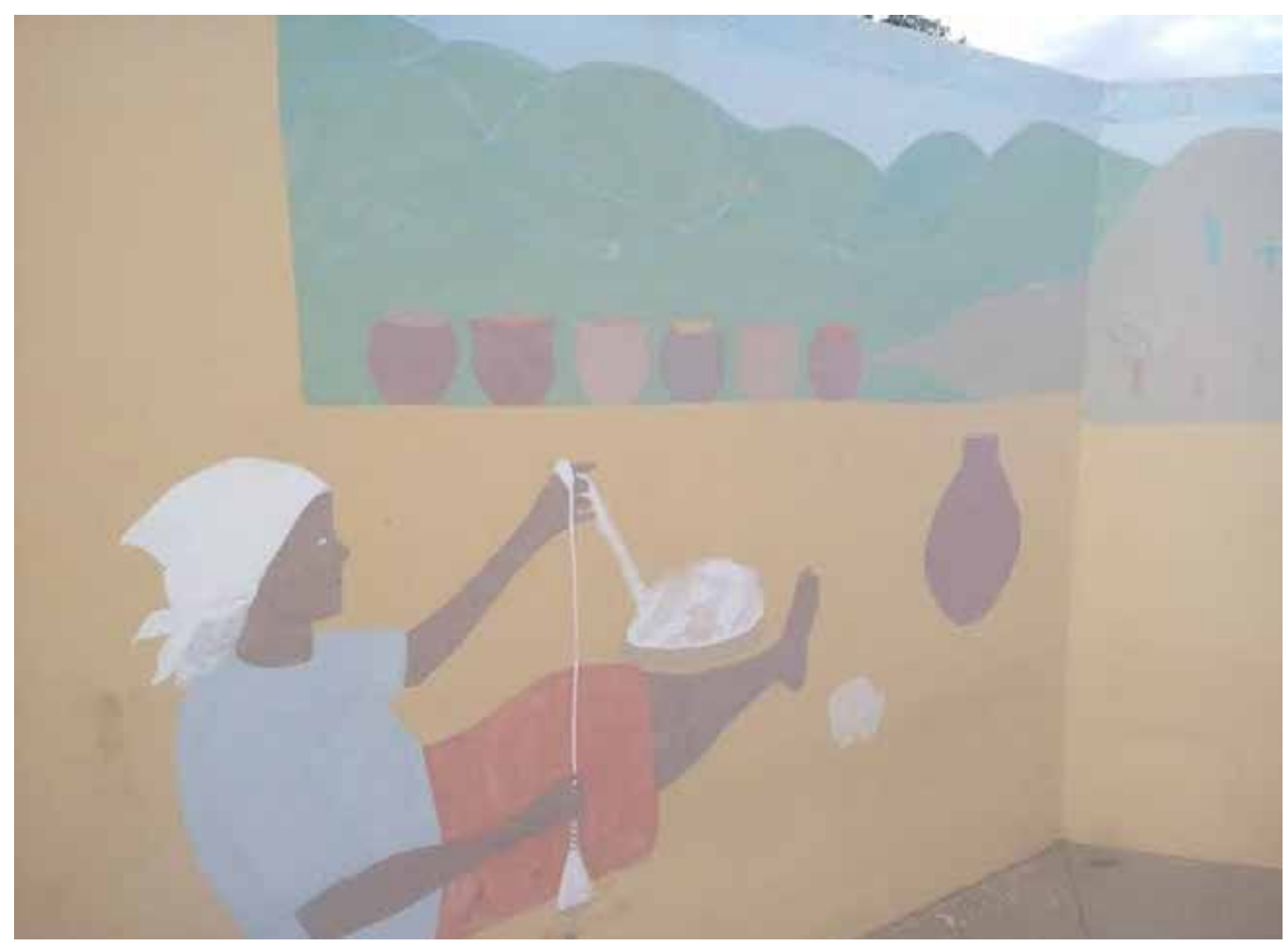

Figura 2 - Mural feito pelos alunos da Escola Quilombola Prof. Rosa Doralina Mendes. Projeto "Expressões Artísticas nas Escolas da Comunidade". Foto Madalena Zaccara, 2015.

Palmares, publicado no Diário Oficial da União, em 11/09/1998 (apud LEITE, 2010).

4. Entende-se por comunidades quilombolas certificadas todas aquelas que manifestaram a afirmação da sua identidade étnica como comunidades remanescentes de quilombos e tiveram seus dados incluídos no cadastro geral junto a FCP conforme o Art. 3) do Decreto 4.887/2003: “§ 4) a autodefinição de que trata o § 1) do art. 2) deste Decreto será inscrita no Cadastro Geral junto à Fundação Cultural Palmares, que expedirá certidão respectiva na forma do regulamento "(apud SILVA, 2013, p. 29).

5. A Associação luta pelo direito da comunidade quilombola de Conceição das Crioulas ao seu território e pela sustentabilidade dessas famílias. Nesse sentido, produzem, de forma sustentável, artesanatos da fibra do caroá, que contam a história e reafirmam a identidade étnica e cultural do povo quilombola, fortalecendo, ainda, a organização política local. Fonte: site da AQCC. Disponível em: http://www.caatingacerrado.com. br/aqcc-associacao-quilombola-de-conceicaodas-crioulas-pe/. Acesso em: 20 ago. 2015.

6. O Crioulas Vídeo é uma equipe de produção de vídeo formada por jovens da comunidade. Para a criação desse grupo foi feita uma escolha entre jovens da comunidade efetuada de forma conjunta. Foram selecionados: Marta Adelaide, Adalmir José, Martinho Mendes, Francisco Mendes, Joséane de Oliveira e Reginaldo António. Hoje, o acervo das Crioulas Vídeo tem vários filmes e seis documentários.

7. Entrevista concedida a Madalena Zaccara, Conceição das Crioulas, mar. 2015.

8. Entrevista concedida a Madalena Zaccara, dez. 2013.

9. Marcia Jucilene Nascimento. Entrevista concedida a Madalena Zaccara, 2015. 


\section{REFERÊNCIAS}

ARARIPE, André; NASCIMENTO Erika (Org.). Sertão Quilombola: a formação dos quilombos no sertão pernambucano. Recife: Publicação do Centro Cultural Luiz Freire. Governo do Estado de Pernambuco, 2008.

BAUMAN, Zygmunt. Em busca da política. Rio de Janeiro: Zahar Editora, 2000.

BOURRIAUD, Nicolas. Pós-produção. Como a arte programa o mundo contemporâneo. São Paulo: Martins Fontes, 2009.

CAMARGO, Oswaldo de (Org.). A razão da chama. Antologia de poetas negros brasileiros. São Paulo: GRD, 1986.

CARRION, Dirce (Coord.). Olhares Cruzados, Brasil Etiópia. Kembata, Conceição das Crioulas. São Paulo: Editora Reflexo, 2013.

CARVALHO, Marcus J. M de. Liberdade, rotinas e rupturas do escravismo no Recife. 18221850. Recife: Editora da Universidade Federal de Pernambuco, 2010.

CRIOULAS VÍDEO. In: ID10: com 10 anos o Identidades esclarece-se e dá-se a conhecer. Porto: Gesto, 2007.

DELEUZE, Gilles. O ato da criação. A obra de arte não é um instrumento de comunicação. Folha de São Paulo, São Paulo 27 de junho de 1999.

FARIA, Monica. Mungunzá ou Cachupa: o direito à conquista e à descoberta de uma nova receita pedagógica. In: PAIVA, José Carlos de; MARTINS, Catarina S. (Org.). Investigar a partir da acçao intercultural. ID -CAI (Coletivo de Ação e Investigação). Porto: Gesto, 2011.

FOUCAULT, Michel. Vigiar e punir: história da violência nas prisões. 7. ed. Petrópolis: Vozes, 1989.

HALL, Stuart. A identidade cultural na pósmodernidade. Rio de Janeiro: DP\&A, 2006.

LEITE, Maria Jorge dos Santos. Conceição das Crioulas: Terra, Mulher e Política. Sankofa. Revista de História da África e de Estudos da Diáspora Africana, ano III, n. 6, dez./2010. Disponível em: file:///C:/Users/mada/Pictures/88789126256-1-SM.pdf. Acesso em: 23 ago. 2015.
PAIVA, José Carlos de. ARTE/desenvolvimento. Tese (Doutorado) - Faculdade de Belas Artes, Universidade do Porto. Porto, 2009.

Entrada de leão, saída de cordeiro. In: ID10: com 10 anos o identidades esclarece-se e dá-se a conhecer. Porto: Gesto, 2007.

No Sertão pernambucano à procura de uma imagem mais nítida do descontentamento como artistas, saboreando mugunzá. In: PAIVA, José Carlos de; MARTINS, Catarina S. (Orgs.). Investigar a partir da acçao intercultural. ID -CAI (Coletivo de Ação e Investigação). Porto: Gesto, 2011.

QUINTAS Fatima. Sexo à moda patriarcal. $O$ feminino e o masculino na obra de Gilberto Freyre. São Paulo: Global, 2008.

RANCIÈRE, Jacques. A partilha do sensível: estética e política. São Paulo: Editora 34, 2009.

SILVA, Gilvania Maria. Meus primeiros passos na busca de pertencer a Conceição das Crioulas. In: CARRION, Dirce (Coord.). Olhares Cruzados, Brasil Etiópia. Kembata, Conceição das Crioulas. São Paulo: Editora Reflexo, 2013.

SOUZA LEAO, Débora de; ALBUQUERQUE, Flávio Rabelo Versiani; VERGOLINO José Raimundo Oliveira. Financiamento e organização do Tráfico de Escravos para Pernambuco no Século XIX. Disponível em: http://www.anpec. org.br/revista/aprovados/Escravos.pdf. Acesso em: 20 ago. 2015.

VIDAL Carlos. Definição da arte política. Lisboa: Fenda, 1997.

ZACCARA, Madalena. Reflexões sobre identidade, periferia e o sistema de internacionalização da arte contemporânea. In: SILVA, Maria Betânia; WILNER, Renata; ZACCARA, Madalena (Org.). Arte Cultura e Memória. Recife: Editora da Universidade Federal de Pernambuco, 2012.

Partidas e Regressos: a atuação do movimento IDENTIDADES no arquipélago de Cabo Verde. ENCONTRO DA ANPAP, 23., 2014. Ecossistemas Artísticos. Anais... Disponível em: http://www.anpap.org.br/anais/2014/ANAIS/ Comit\%C3\%AAs/1\%20CHTCA/Madalena\%20 Zaccara.pdf. 


\section{SOBRE A AUTORA}

Madalena Zaccara possui graduação em Arquitetura e Urbanismo pela Universidade Federal de Pernambuco (UFPE), bacharelado em Direito pela Universidade Católica de Pernambuco (UNICAP), mestrado (DEA) em História e Civilizações - Université Toulouse II, Toulouse, França e doutorado em História da Arte - Université Toulouse II, também em Toulouse, França, como bolsista Capes. Tem pós-doutorado pela Escola de Belas Artes da Universidade de Porto, Portugal, também como bolsista Capes. Atualmente é Professor Associado III da Universidade Federal de Pernambuco. Ensina no Programa Associado de Pós Graduação em Artes Visuais UFPE-UFPB. Lidera o grupo de pesquisa "Arte, Cultura e Memória" que se volta para a pesquisa da História e Teoria das Artes Visuais no Brasil com ênfase para o Nordeste. Atua principalmente nos seguintes temas: História da Arte e Crítica de Arte. É membro da Associação Nacional dos Pesquisadores de Artes Plásticas (ANPAP), da FAEB (Federação dos Arte Educadores Brasileiros) e do Instituto de Investigação em Arte, Design e Sociedade I2ADS (Porto, Portugal). É representante da ANPAP em Pernambuco e membro do Comitê de Teoria, História e Crítica de Arte desta associação. Tem vários livros, capítulos de livros e artigos publicados. Endereço eletrônico: madazaccara@gmail.com. 